\title{
Comparative study of children with calciopaenic and phosphopaenic rickets seen at Chris Hani Baragwanath Hospital
}

\author{
Dr F Agaba MBBCh, FCPaed(SA), MMed \\ Department of Paediatrics, Charlotte Maxeke Academic Hospital and Faculty of Health Sciences, \\ University of the Witwatersrand, Johannesburg, South Africa \\ Dr JM Pettifor MBBCh, FCPaed(SA), PhD(Med) \\ Department of Paediatrics and MRC/Wits Developmental Pathways for Health Research Unit,
}

Chris Hani Baragwanath Academic Hospital and Faculty of Health Sciences, University of the Witwatersrand, Johannesburg, South Africa Dr K Thandrayen MBBCh, FCPaed(SA), MMed, PhD, Certificate in Endocrinology and Metabolism (Paeds) Department of Paediatrics, Chris Hani Baragwanath Academic Hospital and Faculty of Health Sciences, University of the Witwatersrand, Johannesburg, South Africa

\author{
Corresponding author: \\ Dr K Thandrayan \\ PO Box 832 \\ 2061 Bassonia \\ Cell: +27837792574 \\ Tel: +27119331530 (office) \\ Fax: 0865534540 \\ Email: kebashni.thandrayen@wits.ac.za
}

This research was conducted in partial fulfilment of the requirements for the degree of Masters of Medicine in the branch of Paediatrics to the Faculty of Health Sciences, University of the Witwatersrand, Johannesburg, 2015.

\begin{abstract}
Introduction: The majority of causes of rickets can be divided into two large pathogenic groups, namely calciopaenic and phosphopaenic. Few studies have compared the clinical and biochemical presentations of the two forms of rickets. The aim of this study was to compare the demographic, clinical and biochemical presentations and response to therapy of children with calciopaenic and phosphopaenic rickets.

Methodology: The study is a retrospective chart review of children diagnosed with rickets at Chris Hani Baragwanath Academic Hospital (CHBAH) in Johannesburg, South Africa, between 2006 and 2012. The radiological response to therapy was evaluated using the Thacher scoring system to assess the severity of rickets.

Results: The study comprises 112 patients from 2 months to 18 years of age diagnosed with rickets (53\% with calciopaenic rickets and $47 \%$ with phosphopaenic rickets). The calciopaenic group was younger than the phosphopaenic group (20 [7-26] vs 36 [24-51] months; $\mathrm{p}<0.001)$, but the phosphopaenic group was more severely stunted than the calciopaenic group at presentation (HAZ scores -3.3 [ -4.5 to -2.1$]$ vs -2 [ -3.4 to 0.7$] ; \mathrm{p}<0.001$ ).

Following treatment, $75 \%$ of patients in the calciopaenic group had biomarkers that had normalised completely within a median of $13(9-18)$ weeks while only $10 \%$ in the phosphopaenic group had normalised within a median of 17 (17-50) weeks. Radiological healing in response to treatment was better in the calciopaenic group compared to the phosphopaenic group $(67.5 \%$ vs $18 \%$; p-value $<0.01)$.

Conclusion: Calciopaenic rickets (mainly vitamin D deficiency) presented at a younger age and response to therapy was better compared to phosphopaenic rickets (mainly X-linked hypophosphataemic rickets). This study highlights the significant differences between calciopaenic and phosphopaenic rickets, which may be helpful to attending orthopaedic surgeons and paediatricians in differentiating between these two groups of rickets and in the management thereof.

Summary of abstract: This study highlights the differences between calciopaenic and phosphopaenic rickets, which may be of assistance to attending orthopaedic surgeons and paediatricians in the management of rickets. The study shows that in children with calciopaenic rickets, the majority are vitamin D deficient, and present at a younger age with craniotabes and less severe lower limb deformities compared to children with phosphopaenic rickets who mainly have $\mathrm{X}$-linked hypophosphataemic rickets and are severely short in stature and have genu valgum deformities. The medical management of the two types of rickets differs and response to medical therapy is better in the calciopaenic compared to the phosphopaenic group.
\end{abstract}

Key words: rickets, calciopaenic, phosphopaenic, Thacher score, Johannesburg, X-linked hypophosphataemic rickets, vitamin D deficiency 


\section{Introduction}

With the discovery of the role of vitamin $\mathrm{D}$ in the pathogenesis of rickets nearly a century ago, the various causes were divided into those responsive to and those resistant to vitamin D therapy. ${ }^{1}$ As the pathogenesis of various types of rickets became more apparent, the underlying mechanisms were classified into those associated primarily with disturbances in calcium (calciopaenic rickets) and those related to perturbed phosphate homeostasis (phosphopaenic rickets). ${ }^{2}$ Table I lists the different causes of these two forms of rickets. ${ }^{2,3}$

\section{Table I: The causes of calciopaenic and phosphopaenic rickets}

\section{Calciopaenic causes}

a. Abnormalities in vitamin D

metabolism

- Nutritional rickets

- dietary deficiency of vitamin D

- inadequate exposure to sunlight

- Impaired absorption of vitamin D - steatorrhea, e.g. coeliac disease - biliary obstruction, e.g. biliary atresia

- Impaired hydroxylation of vitamin D to 25-hydroxyvitamin D

- liver immaturity

- prematurity

- Increased metabolism of vitamin D

$\circ$ anticonvulsant drugs, e.g. phenobarbitone

- Decreased renal synthesis of 1,25-dihydroxy-vitamin D

$\circ$ renal failure

- vitamin D-dependency rickets (type I)

- End-organ resistance to 1,25-dihydroxy-vitamin D

- vitamin D-dependency rickets (Type II)

b. Dietary deficiency of calcium

- Diets deficient in dairy products

Table II: Biochemical differences between calciopaenic and phosphopaenic rickets

\begin{tabular}{l|c|c|}
\hline Biochemistry & $\begin{array}{c}\text { Calciopaenic } \\
\text { rickets }\end{array}$ & $\begin{array}{c}\text { Phosphopaenic } \\
\text { rickets }\end{array}$ \\
\hline Serum calcium $(2.15-2.75 \mathrm{mmol} / \mathrm{L})$ & $\downarrow$ or $\mathrm{N}$ & $\mathrm{N}$ \\
\hdashline Serum inorganic phosphate $(1.30-2.6 \mathrm{mmol} / \mathrm{L})^{*}$ & $\downarrow$ or $\mathrm{N}$ & $\downarrow \downarrow$ \\
\hline Serum 25(OH)D $(>30 \mathrm{nmol} / \mathrm{L})$ & $\begin{array}{c}\downarrow \text { (vitamin } \mathrm{D} \\
\text { deficiency only) }\end{array}$ & $\mathrm{N}$ \\
\hline Serum alkaline phosphatase $(100-350 \mathrm{IU} / \mathrm{L})^{*}$ & $\uparrow \uparrow$ & $\uparrow$ \\
\hline Serum parathyroid hormone $(1.1-6.9 \mathrm{pmol} / \mathrm{L})$ & $\uparrow \uparrow$ & $\mathrm{N}$ or slightly $\uparrow$ \\
\hline Normal values shown within brackets; ${ }^{*}$ Age-dependent & & \\
\hline
\end{tabular}

The biochemical findings differ between the two groups of rickets while the skeletal changes are clinically similar ${ }^{3,4}$ although there are some differences in clinical presentation. Management of rickets depends on the underlying cause. Previous studies suggest that calciopaenic rickets presents earlier than phosphopaenic rickets., ${ }^{5,6}$ The severe calciopaenic form of rickets usually presents with delayed motor milestones, severe bone pain and deformities, and hypotonia, ${ }^{7}$ while the common form of phosphopaenic rickets presents with short stature and leg deformities. Table II shows the important differences in the biochemical findings between calciopaenic and phosphopaenic rickets. ${ }^{1,3,4,8}$

The commonest cause of calciopaenic rickets is vitamin $\mathrm{D}$ deficiency which is easily corrected by oral administration of vitamin D. ${ }^{3}$ X-linked hypophosphataemic rickets is the most common form of phosphopaenic rickets and is currently treated with calcitriol and phosphate supplements. ${ }^{9,10}$

In South Africa, there are little published data on the prevalence and presentation of the different types of rickets in children. The clinical, biochemical and radiological differences between calciopaenic and phosphopaenic rickets may not be easily recognised by the attending health care workers in primary and secondary health care facilities. This study aims to describe the demographic, clinical, biochemical and radiological findings together with the management of these children presenting with calciopaenic and phosphopaenic rickets to the Metabolic Bone Disease Clinic in Johannesburg.

\section{Methodology}

The study was a retrospective, descriptive study of all the rachitic patients (a total of 112 patients from 1 month to 18 years of age) referred to the clinic. No patients were excluded from the study. The records of patients who were reviewed were seen at the Paediatric Metabolic Bone Disease Clinic at Chris Hani Baragwanath Academic Hospital (CHBAH), the major referral hospital for the communities of Soweto, Johannesburg and surrounding areas from January 2006 until December 2012.

The classification of calciopaenic and phosphopaenic rickets was based on the final diagnosis of the attending clinicians. The final diagnosis was based on the biochemical changes on presentation and on the response of the rickets to the prescribed therapy as these two types of rickets are treated differently. The diagnosis of rickets was confirmed on radiographs of the wrists or knees. 
Information on the demographic, clinical, radiological and biochemical findings were collected. Radiological findings were evaluated by FA and thereafter checked by KT using the Thacher scoring system for severity of rickets. ${ }^{11}$

Data was analysed using Statistica statistical software version 10.0 (Stat soft, USA). Continuous variables were described using medians and interquartile ranges (IQR) because they were not normally distributed. Categorical variables were described using percentages. Comparisons between patients with calciopaenic and phosphopaenic rickets were done using chi-squared or Fisher's exact statistical methods for categorical data and Mann-Whitney U test for continuous variables. A p-value of $<0.05$ was considered to be statistically significant.

Height for age $\mathrm{Z}$ score (HAZ) and weight for age $\mathrm{Z}$ score (WAZ) were calculated using the WHO Anthroplus software (http: / / www.who.int/growthref/tools/en).

The study was approved by the Human Research Ethics Committee (HREC) of the University of the Witwatersrand (approval number M130225). Permission from the Chief Executive Officer at CHBAH was obtained to conduct the study.

\section{Results}

\section{Demographic data}

This study comprised 112 patients aged between 2 months and 18 years diagnosed with rickets. Fifty-nine patients were classified as having calciopaenic rickets $(52.7 \%)$ and 53 with phosphopaenic rickets $(47.3 \%)$. There was a greater number of males compared to females in the calciopaenic group (38 [64\%] vs 21 [36\%]; $\mathrm{p}<0.01)$ and a greater number of females compared to males in the phosphopaenic group (35 [66\%] vs 18 [34\%]; p<0.01). In both the calciopaenic and phosphopaenic groups, the majority of children were black
African (51 [87\%] and 45 [84\%] respectively) with the remaining $13 \%$ and $16 \%$ comprising Indian/Pakistani, white or mixed ancestry ethnic groups.

In both groups, more than $80 \%$ of children were from Gauteng and the rest from other provinces within South Africa. In both the groups, more than two-thirds of the patients were referred from peripheral hospitals or a paediatrician, followed by orthopaedic surgeons, clinics and general practitioners. In the calciopaenic group, two (3\%) patients had a family history of rickets (one patient had an elder sibling with vitamin D deficiency and the other patient had an uncle who had had a possible diagnosis of rickets but had not been treated). In the phosphopaenic group, $22(42 \%)$ had a family history of rickets.

\section{Age and anthropometric measurements at presentation and referral}

The ages at initial referral and at the most recent follow-up visit together with the anthropometric measurements at the initial referral of the patients are shown in Table III. The calciopaenic group presented at a younger age compared to the phosphopaenic group (20 [7-26] vs 36 [24-51] months; $\mathrm{p}<0.001)$, but the phosphopaenic group were more stunted (HAZ scores -3.3 [ -4.5 to -2.1$]$ vs -2 [ -3.4 to 0.7$]$ respectively; $\mathrm{p}<0.001)$.

\section{Pathogenesis of rickets in the calciopaenic and phosphopaenic groups}

In the calciopaenic group, the majority of patients $(54 / 59)$ presented with vitamin D deficiency rickets; two presented with probably dietary calcium deficiency rickets; two patients were diagnosed as having vitamin D dependency rickets (VDDR) type I (one of whom was confirmed on genetic testing); and one child had renal osteodystrophy.

\section{Table III: Chronological ages and anthropometric measurements in the calciopaenic and phosphopaenic groups}

\begin{tabular}{|c|c|c|c|c|}
\hline \multirow{2}{*}{ Chronological ages and anthropometric measurements } & $\begin{array}{l}\text { All patients } \\
\qquad(\mathrm{n}=112)\end{array}$ & $\begin{array}{l}\text { Calciopaenic } \\
\text { rickets }(n=59)\end{array}$ & $\begin{array}{l}\text { Phosphopaenic } \\
\text { rickets }(n=53)\end{array}$ & \multirow{2}{*}{ P-value } \\
\hline & $\begin{array}{c}\text { Median } \\
\text { (IQ range) }\end{array}$ & $\begin{array}{l}\text { Median } \\
\text { (IQ range) }\end{array}$ & $\begin{array}{l}\text { Median } \\
\text { (IQ range) }\end{array}$ & \\
\hline Age at diagnosis or at initial presentation (months) & $24(16-41)$ & $20(7-26)$ & $36(24-51)$ & $<0.001$ \\
\hline Age at first consultation at Metabolic Bone Disease Clinic (months) & $26(17.5-48)$ & $20(7-26)$ & $41(25-71)$ & $<0.001$ \\
\hline Age at most recent follow-up (months) & $42(24-93)$ & $27(15-36)$ & $89(50-132)$ & $<0.001$ \\
\hline Weight (kg) & $10.3(7.5-11.3)$ & $9.2(6.5-11.2)$ & $12(9.4-16)$ & $<0.001$ \\
\hline WAZ score & $-1.6(-2.9$ to -0.4$)$ & $-1.2(-3$ to -0.01$)$ & $-1.9(-2.7$ to -1.3$)$ & 0.05 \\
\hline Height $(\mathrm{cm})$ & $80(71-88.4)$ & $76(64-83)$ & $85(77-96)$ & $<0.001$ \\
\hline HAZ score & $-2.9(-3.9$ to -1.4$)$ & $-2(-3.4$ to -0.7$)$ & $-3.3(-4.5$ to -2.1$)$ & $<0.001$ \\
\hline
\end{tabular}


In the phosphopaenic group, 33/53 patients (62\%) presented with a clinical diagnosis of X-linked hypophosphataemic rickets. The remaining 20 patients $(38 \%)$ in the phosphopaenic group presented with rickets secondary to other renal tubulopathies (proximal RTA 9 [17\%], distal RTA $4[8 \%]$ ) and sporadic hypophosphataemic rickets $(7[13 \%])$

\section{Clinical characteristic features of rickets}

The most common clinical presenting features in both groups were widened wrists, rachitic rosary and frontal bossing in more than $80 \%$ of patients. There was a greater number of patients in the phosphopaenic group presenting with genu valgum of the lower limbs compared to those patients with calciopaenic rickets $(64 \%$ vs $32 \%$; $\mathrm{p}<0.01)$. Craniotabes and a lack of lower limb deformities were the two clinical features more prevalent in the calciopaenic group compared to the phosphopaenic group (27\% vs $11 \%$; $\mathrm{p}<0.05$ and $27 \%$ vs $4 \%$; $\mathrm{p}<0.01$ respectively).

\section{Results of biomarkers on presentation and on follow-up or discharge}

Table IV shows the baseline biochemical variables on referral and on one-year follow-up or at discharge (after therapy) of the calciopaenic and phosphopaenic groups of patients. Total serum calcium levels were significantly lower in the calciopaenic group $(2.1$ [2-2.3] $\mathrm{mmol} / \mathrm{L})$ compared to the phosphopaenic group (2.3 [2.1-2.4] $\mathrm{mmol} / \mathrm{L})$. In the calciopaenic group, $41 \%(24 / 58)$ had hypocalcaemia, while in the phosphopaenic group, $27 \%$ $(14 / 52)$ were hypocalcaemic. The calciopaenic group also had significantly higher serum parathyroid hormone (PTH) and alkaline phosphatase (ALP) levels. The median phosphate level was lower in the phosphopaenic group than the calciopaenic group $(\mathrm{p}<0.001)$. In the phosphopaenic group, $96 \%(50 / 52)$ were phosphopaenic compared to the $60 \%(34 / 57)$ in the calciopaenic group. The ionised calcium and 25-hydroxyvitamin D $(25(\mathrm{OH}) \mathrm{D})$ levels were not significantly different, but the number of patients with measurements was small in both groups.

At one-year follow-up or on discharge after therapy, total serum calcium levels in both groups were within the normal reference range but serum inorganic phosphate levels remained low in the phosphopaenic group $(p<0.001)$. After treatment, data were available on 96 children, $35 / 47(75 \%)$ in the calciopaenic group had biochemical markers of rickets that had normalised completely within a median of 13 (9-18) weeks while only $5 / 49(10 \%)$ in the phosphopaenic group had within a median of 17 (17-50) weeks ( $75 \%$ vs $10 \%$; p value $<0.001$ ).

Table IV: Baseline measurements of biomarkers on referral and on one-year follow-up or at discharge (after therapy) in patients with calciopaenic and phosphopaenic rickets

\begin{tabular}{|c|c|c|c|c|c|c|c|}
\hline \multirow[b]{2}{*}{ Biomarkers on referral } & \multirow[b]{2}{*}{ n } & All groups & \multicolumn{2}{|c|}{ Calciopaenic rickets } & \multicolumn{2}{|c|}{ Phosphopaenic rickets } & \multirow[b]{2}{*}{ P-value } \\
\hline & & $\begin{array}{c}\text { Median } \\
\text { (IQ range) }\end{array}$ & $\mathbf{n}$ & $\begin{array}{c}\text { Median } \\
\text { (IQ range) }\end{array}$ & $\mathbf{n}$ & $\begin{array}{c}\text { Median } \\
\text { (IQ range) }\end{array}$ & \\
\hline Calcium (ionised) (mmol/L) & 27 & $1.3(1.2-1.3)$ & 11 & $1.2(0.9-1.3)$ & 16 & $1.3(1.2-1.3)$ & 0.05 \\
\hline Total serum calcium $(\mathrm{mmol} / \mathrm{L})$ & 110 & $2.2(2.1-2.3)$ & 58 & $2.1(2.0-2.3)$ & 52 & $2.3(2.1-2.4)$ & $<0.01$ \\
\hline Phosphate (mmol/L) & 109 & $0.9(0.8-1.3)$ & 57 & $1.1(0.9-1.6)$ & 52 & $0.8(0.7-0.9)$ & $<0.001$ \\
\hline Serum alkaline phosphatase (IU/L) & 105 & 711 (469-1053) & 55 & 864 (493-1484) & 50 & 577 (464-893) & 0.03 \\
\hline Serum parathyroid Hormone (pmol/L) & 96 & $12(5.7-26.1)$ & 49 & $21(12-36)$ & 47 & $7.4(4.6-16.1)$ & $<0.001$ \\
\hline Serum 25(OH)D (nmol/L) & 42 & $58.2(32.4-84.6)$ & 24 & $53(32-82)$ & 18 & $69(34-85)$ & 0.3 \\
\hline Biomarkers at 1-year follow-up or discharge & $\mathrm{n}$ & $\begin{array}{l}\text { Median } \\
\text { (IQ range) }\end{array}$ & $\mathbf{n}$ & $\begin{array}{l}\text { Median } \\
\text { (IQ range) }\end{array}$ & $\mathbf{n}$ & $\begin{array}{l}\text { Median } \\
\text { (IQ range) }\end{array}$ & P-value* \\
\hline Calcium (Ionised) (mmol/L) & 5 & $1.3(1.2-1.3)$ & 3 & $1.3(1.2-1.3)$ & 2 & $1.3(2.2-2.4)$ & 0.4 \\
\hline Total serum calcium $(\mathrm{mmol} / \mathrm{L})$ & 93 & $2.3(2.2-2.4)$ & 46 & $2.3(2.2-2.4)$ & 47 & $2.3(2.2-2.3)$ & 0.2 \\
\hline Phosphate (mmol/L) & 94 & $1.3(0.8-1.7)$ & 46 & $1.7(1.4-1.8)$ & 48 & $0.87(0.76-1.2)$ & $<0.001$ \\
\hline Serum alkaline phosphatase (IU/L) & 94 & $452(315-681)$ & 47 & $379(272-543)$ & 47 & $600(375-781)$ & $<0.001$ \\
\hline Serum parathyroid hormone (pmol/L) & 82 & $5.1(3.4-9.6)$ & 39 & $4.7(3-8.6)$ & 43 & $5.5(3.7-12.3)$ & 0.5 \\
\hline Thacher score & $\mathbf{n}$ & $\begin{array}{l}\text { Median } \\
\text { (IQ range) }\end{array}$ & $\mathbf{n}$ & $\begin{array}{l}\text { Median } \\
\text { (IQ range) }\end{array}$ & n & $\begin{array}{l}\text { Median } \\
\text { (IQ range) }\end{array}$ & P-value* \\
\hline Initial Thacher score & 94 & $9(6-10)$ & 47 & $9(4-10)$ & 47 & $10(6-10)$ & 0.1 \\
\hline Thacher score at 1-year follow-up or on discharge & 78 & $2(0-7)$ & 40 & $0(0-2)$ & 38 & $6(1.5-8)$ & $<0.001$ \\
\hline
\end{tabular}


The grading of radiological findings of rickets using the Thacher scoring system

The Thacher scoring system was utilised to assess the severity of the radiological features of rickets at the wrist and/or knee on initial presentation and at one-year follow-up or on discharge (Table IV). The initial median Thacher score for all patients was 9 (IQR 6-10). There was no difference in the Thacher score at presentation between the phosphopaenic and calciopaenic groups of patients (median 10 [IQR 6-10] vs 9 [IQR 4-10]; $\mathrm{p}=0.12$ ). At oneyear follow-up or on discharge, the Thacher score had fallen but remained high in the phosphopaenic group while in the calciopaenic group it had returned to nearly normal $(<1.5)$ (median 6 [IQR 1.5-8] and 0 [IQR 0-2] respectively; $\mathrm{p}<0.001)$.

In the calciopaenic group of patients, $27(67.5 \%)$ patients had resolution of the radiological features (Thacher score $\leq 1.5$ ) at the time of discharge. Not all children had a radiographic assessment on discharge, especially if they had improved clinically and biochemically. Some were also discharged before complete healing because the clinical and biochemical response had been good. At follow-up in the phosphopaenic group, seven $(18 \%)$ had resolution of radiological features of rickets while 31 (82\%) did not show complete resolution of radiological features. Thus, radiological healing in response to treatment was better in the calciopaenic group compared to the phosphopaenic group $(67.5 \%$ vs $18 \%$; p-value $<0.001)$.

\section{Treatment of the rickets}

Of the 112 patients, 41 (37\%) had been started on treatment prior to their referral to our clinic as shown in Figure 1. Twenty-five of the 41 patients referred on treatment had calciopaenic rickets and the remaining 16 had phosphopaenic rickets. Of the 16 patients with phosphopaenic rickets, $50 \%$ (8) were being treated as calciopaenic rickets on vitamin $\mathrm{D}$ at the time of referral.

\section{Discussion}

Although the current literature on rickets does highlight the salient features and management of the various forms of rickets, this study provides an overview of the differences between calciopaenic and phosphopaenic rickets so that these patients can be more easily recognised early in the disease process and thereafter treated or referred to a tertiary centre for further management if warranted.

This retrospective study compares an almost equal number of calciopaenic and phosphopaenic patients (52.7\% vs $47.3 \%)$ presenting to the Paediatric Metabolic Bone Disease Clinic at CHBAH between 2006 and 2012. The majority of patients were referred by paediatricians $(36.6 \%)$, peripheral hospitals $(33 \%)$ and by the orthopaedic surgeons within the hospital's major referral area.

The preponderance of female patients in the hypophosphataemic group ( $66 \%$ female) is in keeping with the majority of patients in that group being diagnosed with X-linked hypophosphataemic rickets, $42 \%$ of whom had a family history. These findings are similar to studies from the Republic of Korea and north India, ${ }^{5,12}$ which found a greater number of female patients $(82 \%$ and $70.5 \%$ respectively) than male patients with hypophosphataemic rickets. In these studies, a positive family history was noted in $29 \%$ and $35.3 \%$ respectively.

In the calciopaenic group of rickets, the most common cause of rickets was vitamin D deficiency. In the phosphopaenic group, $75 \%$ of patients presented with suspected X-linked hypophosphataemia (XLH) and sporadic hypophosphataemic rickets while the remaining $25 \%$ presented with phosphopaenic rickets secondary to an underlying renal tubular dysfunction. Unlike an Indian study, in which two-thirds of patients with refractory rickets were found to have renal tubular acidosis (RTA), the majority being distal RTA, ${ }^{13}$ in the present study only a quarter had RTA.

The younger age of the calciopaenic patients (20 months compared to 36 months in the phosphopaenic group) reflects the characteristically earlier age of presentation of vitamin D deficiency rickets. As was noted in Mumbai (western India), children with vitamin D deficiency rickets or renal tubular acidosis more frequently presented in the first 2 years of life while those with X-linked hypophosphataemic rickets after 2 years of age, ${ }^{13}$ findings similar to the patterns described in this study.

The phosphopaenic group of children were also more stunted than the calciopaenic group at the time of referral (HAZ score -3.3 vs $-2 ; \mathrm{p}<0.001$ ), reflecting the more chronic nature of X-linked hypophosphataemic rickets $(\mathrm{XLH})$ compared to vitamin D deficiency rickets.

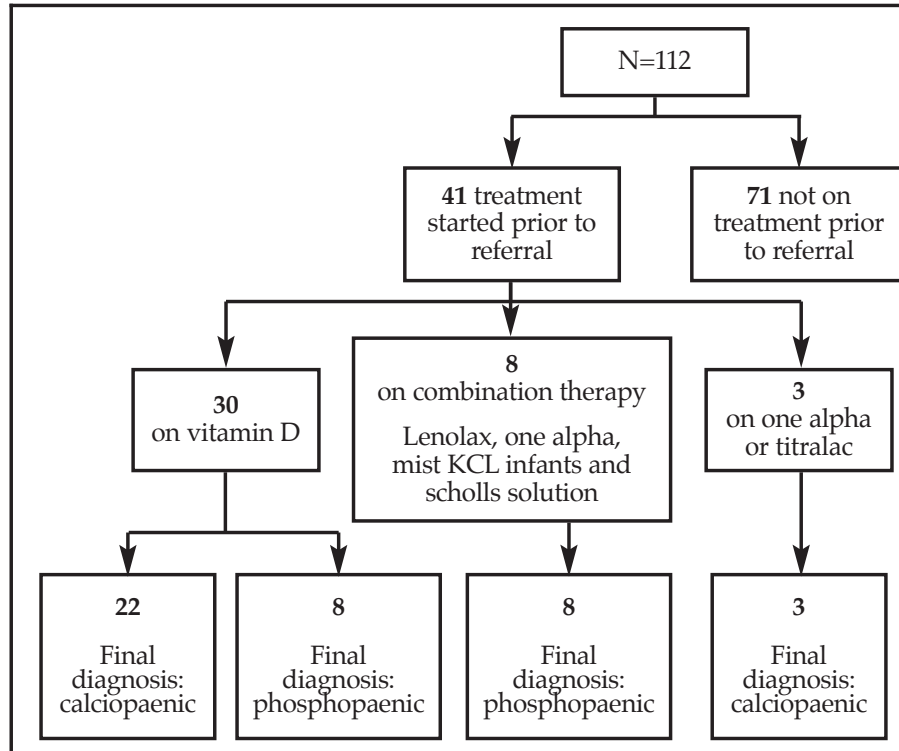

Figure 1. Flow diagram demonstrates treatment at the time of referral of children with suspected rickets to the Paediatric Metabolic Bone Disease clinic 
The most common clinical presenting features in both calciopaenic and phosphopaenic groups of rickets were widened wrists, rachitic rosary and frontal bossing $(>80 \%$ of patients), which is similar to that reported by Soliman et al. ${ }^{14}$ who studied infants and young children with vitamin D deficiency rickets. Another study on nutritional rickets in Kenya also reported on the most common clinical findings being swelling of the wrists (89\%), frontal bossing $(67 \%)$ and rachitic rosary of the chest $(54 \%) .{ }^{15}$ Thacher et al. screened Nigerian children with rickets and found that there were five clinical features of rickets that independently predicted active rickets of which wrist and costochondral enlargement had the highest positive predictive values for active rickets which supports the clinical findings of this study. ${ }^{16}$

Surprisingly in this study, 25(OH)D levels were found to be in the normal range $(>50 \mathrm{nmol} / \mathrm{L})$ in the majority of children with both types of rickets. The most likely explanation for these apparently inappropriate levels of $25(\mathrm{OH}) \mathrm{D}$ in the calciopaenic group is because over one-third of patients were on vitamin D treatment on referral. Furthermore, only 24 of 59 patients with calciopaenic rickets had their vitamin D status assessed.

Using the Thacher scoring system, the radiological severity of rickets at presentation was similar in the two groups, but at the time of discharge or at 12 months, radiological healing was less evident in the phosphopaenic group than the calciopaenic group ( $18 \%$ vs $67.5 \%$; p-value $<0.001)$. These findings suggest that the majority of patients with phosphopaenic rickets do not heal completely with therapy. This finding highlights the chronic nature of the underlying causes of phosphopaenic rickets and helps differentiate the two types of rickets.

The retrospective nature of this study has limitations, as not all relevant data could be traced. Furthermore, not all clinical findings may have been reported or looked for at the time of initial assessment, thus influencing the prevalence of clinical findings. Finally, $18(16 \%)$ patients at initial consultation did not have X-rays and $34(30 \%)$ patients did not have X-rays after one year of follow-up, thus possibly influencing the interpretation of the radiographic findings.

\section{Conclusion}

In conclusion, this study highlights the differences between calciopaenic and phosphopaenic rickets, which may be of assistance to the attending orthopaedic surgeons and paediatricians in the management of rickets. The study shows that in children with calciopaenic rickets, the majority are vitamin $\mathrm{D}$ deficient, and present at a younger age with craniotabes and less severe lower limb deformities compared to children with phosphopaenic rickets who mainly have X-linked hypophosphataemic rickets and are severely short in stature and have genu valgum deformities. The medical management of the two types of rickets differs and response to medical therapy is better in the calciopaenic compared to the phosphopaenic group.

\section{Compliance with ethics guidelines}

Drs F Agaba, JM Pettifor and K Thandrayen have no conflicts of interest to declare.

This study was self-funded and thus there is no need for disclosure of funding by the authors.

The study was approved by the Human Research Ethics Committee (HREC) of the University of the Witwatersrand (approval number M130225). Permission from the Chief Executive Officer at $\mathrm{CHBAH}$ was obtained to conduct the study.

\section{References}

1. Pettifor JM. Nutritional rickets: deficiency of vitamin $D$, calcium, or both? Am J Clin Nutr. 2004;80(6 Suppl):1725S-9S.

2. Pettifor JM. Nutritional rickets in developing countries. Forum Nutr. 2003;56:176-78.

3. Pettifor JM, Thandrayen K. Rickets and metabolic bone disorders. In: Green RJ, editor. Coovadia's paediatrics and child health. 7th ed. South Africa: Oxford University Press Southern Africa Limited; 2014:224-41.

4. Jagtap VS, Sarathi V, Lila AR, Bandgar T, Menon P, Shah NS. Hypophosphatemic rickets. Indian $J$ Endocrinol Metab. 2012;16(2):177-82.

5. Bhadada SK, Bhansali A, Upreti V, Dutta P, Santosh R, Das S, et al. Hypophosphataemic rickets/osteomalacia: a descriptive analysis. Indian J Med Res. 2010;131:399-404.

6. Tezer H, Siklar Z, Dallar Y, Dogankoc S. Early and severe presentation of vitamin $\mathrm{D}$ deficiency and nutritional rickets among hospitalized infants and the effective factors. Turk J Pediatr. 2009;51(2):110-15.

7. Naude CE, Carey PD, Laubscher R, Fein G, Senekal M. Vitamin $\mathrm{D}$ and calcium status in South African adolescents with alcohol use disorders. Nutrients. 2012;4(8):1076-94.

8. Pettifor JM. Calcium and vitamin d metabolism in children in developing countries. Ann Nutr Metab. 2014;64 Suppl 2:15-22.

9. Holm IA, Econs MJ, Carpenter TO. Familial hypophosphatemia and related disorders. In: Glorieux FH, Pettifor JM, Juppner H, editors. Pediatric bone: biology and diseases. London: Elsevier; 2012:699-726.

10. Linglart A, Biosse-Duplan M, Briot K, Chaussain C, Esterle L, Guillaume-Czitrom $\mathrm{S}$, et al. Therapeutic management of hypophosphatemic rickets from infancy to adulthood. Endocr Connect. 2014;3(1):R13-30.

11. Thacher TD, Fischer PR, Pettifor JM, Lawson JO, Manaster BJ, Reading JC. Radiographic scoring method for the assessment of the severity of nutritional rickets. I Trop Pediatr. 2000;46(3):132-39.

12. Cho HY, Lee BH, Kang JH, Ha IS, Cheong HI, Choi Y. A clinical and molecular genetic study of hypophosphatemic rickets in children. Pediatr Res. 2005;58(2):329-33.

13. Joshi RR, Patil S, Rao S. Clinical and etiological profile of refractory rickets from western India. Indian J Pediatr. 2013;80(7):565-69.

14. Soliman A, De Sanctis V, Adel A, El Awwa A, Bedair S. Clinical, biochemical and radiological manifestations of severe vitamin $\mathrm{d}$ deficiency in adolescents versus children: response to therapy. Georgian Med News. 2012(210):58-64.

15. Edwards JK, Thiongo A, Van den Bergh R, Kizito W, Kosgei RI, Sobry A, et al. Preventable but neglected: rickets in an informal settlement, Nairobi, Kenya. Public Health Action. 2014;4(2):122-27.

16. Thacher TD, Fischer PR, Pettifor JM. The usefulness of clinical features to identify active rickets. Ann Trop Paediatr. 2002;22(3):229-37.

This article is also available online on the SAOA website (www.saoa.org.za) and the SciELO website (www.scielo.org.za). Follow the directions on the Contents page of this journal to access it. 